\title{
Research on Consumer Willingness to Purchase Organic Food Products
}

\author{
Anna Shcherenkov, B.S. Business \\ Erinn Ryen, PhD in Sustainability \\ Assistant Professor of Business \\ Wells College \\ 170 Main Street \\ Aurora, NY 13026, USA
}

\begin{abstract}
This paper presents research on consumer's behavior and willingness to purchase organic food products by analyzing literature previously conducted by other researchers and conducting instigators own research using online survey with the sample size of 208 participants. The main objective of this study is to examine consumer's perceptions towards organic food products that may affect their willingness to purchase (WTP) organic foods. The Pearson correlation test and the regression analysis are conducted to validate or disprove the relationship between the variables. The findings have shown that human health, environmental consciousness, perceived cost, labeling and certification of organic food products influence consumer preferences to purchase organic food products. The study validates that the healthconsciousness is the key factor affecting consumer purchasing decisions of organic foods and accounts to $46 \%$ of the variability in WTP organic food products. This suggests that consumers are aware about health and nutrition benefits of organically grown produce which in turn impacts their purchasing decision. Several limitations are suggested for future study.
\end{abstract}

Keywords: Organic foods, health consciousness, willingness to purchase.

\section{Introduction}

Organic food is one of the fastest growing segments of the retail food market. The total sales of organic products in the United States increased by as much as 83\% between 2007 and 2012 (Cohrssen \& Miller, 2016). Currently, according to Pilar et al. (2018) study, organic food is grown on 50.9 million hectares globally and as noted by Pino et al. (2012), the market continues to expand worldwide at the average rate of $20 \%$ annually. According to Song \& Mansori (2016), in 2014 global sales for organic food products reached \$72 billion in US currency, and 43.7 million hectares of the farmland became certified organic.

Numerous factors have contributed to the progression of organic food products and organic farming including food safety, environmental factors, health concerns, and animal welfare consideration (Cohrssen and Miller, 2016; Madan, 2017; Pilar 2018; Pino et al., 2012; Türk et al., 2016). Organic farming provides an alternative by restricting the usage of synthetic pesticide and chemicals (Klonsky, 2012; Smith, 2012; Song \& Mansori, 2012).

Organic foods have a number of advantages in terms of wellbeing and absence of harmful chemicals that are widely used in conventional production (Bo Won Suh et al., 2015). Extensive research conducted over a number of years has proven that organic foods not only tastes better than conventional foods, but it is better for heathland is safe for the environment as a whole, as it does not contain substances such as genetically modified organisms, pesticides or hormones (Bo Won Suh et al., 2015; Cohrssen \& Miller, 2016; Madan, 2017; Pilar 2018; Pino et al., 2012; Türk et al., 2016).

Organic certification is another factor that influences consumer demand for organic foods. The U.S. regulatory scheme on organic food production is based on the Organic Food Production Act, 1990 (OFPA), which delegates to the USDA the task of regulating organic production, handling and labeling. The OFPA was designed to establish national standards and prevent consumer confusion (Chenglin, 2011).Therefore, organic food production is a legally regulated by the U. S. Department of Agriculture (USDA) and includes the control and certification process from the farm to the market (Cohrssen \& Miller, 2016; Klonsky, 2012; Madan, 2017).

Market itself means - customer, around whom all marketing strategies are formulated and implemented. In ever changing marketing environment, there is a growing concern or awareness among marketers to go for a careful study of the consumer behavior around which all marketing activities are made (Türk \& Erciş, 2017). 
In order to meet competition at the marketplace, the marketing managers are using various methods to add value to the final product which will reach the hands of the consumers. Because of this basic belief that the customer is the center around which the business revolves, marketers can take into account that different groups of consumers pursue different values. Their advertisement approach should be communicated appropriately to increase the effectiveness of the policies directed at encouraging sustainable consumption patterns and promote public confidence in the safety standards of organic farming (Pino et al., 2012). Thus, investigating consumer behavior towards organic foods purchase is one of the inspirational areas of marketing research. Therefore, it is important to find out the factors that motivate consumers to purchase certain organic goods and what will affect their willingness to pay for the product.

The purpose of this study is to examine the consumer's perceptions of the organic food products that may affect their buying intensions. In our study, we will examine how environment consciousness, health consciousness, organic foods certification and cost factors affect consumer willingness to purchase organic food products.

The following research questions were generated to help to accommodate the study goals and to understand the association between four independent variables and one dependent variable.

1. What are the factors that influence consumer's decision to purchase organic foods?

2. To study the relationship of environmental concern and willingness to buy organic foods.

3. To study the relationship of health conscious on willingness to purchase organic foods.

4. Does premium price (cost) affect consumers decision to purchase organic foods?

5. The role of labeling on consumer's food choices.

\section{Literature Review}

\subsection{Factors Towards Purchasing Organic Food Products}

In this modern day's sex roles are evolving, therefore, understanding what makes people in general buy and what makes customer in particular buy is a vital part of business success (Türk \& Erciş, 2017). For instance, gender shows different consumption patterns and perceptions of consumption situations. It is consistent throughout lifetime, influencing customer values and preferences. (Istudor \& Pelau, 2013). Women are becoming more professional and independent, and men are becoming more sensitive and caring; but men and women can differ in terms of traits, information processing, decision styles, and consumption patterns (Istudor \& Pelau, 2013).

In addition to gender, many researchers are in agreement that central motives towards purchasing organic foods include harmless to human health, safer than conventionally produced foods, responsibility of family and well-being (Bo Won Suh et al., 2015; Pino et al., 2012). Besides, several studies have concluded that the main drive for the increase in the consumers demand of organic food products include nutritional benefits, taste, health-conscious, production of high quality, food safety, environmental protection and animal welfare (Bo Won Suh et al., 2015; Cohrssen \& Miller, 2016; Madan, 2017; Pilar 2018; Pino et al., 2012; Türk et al., 2016).

While, Cohrssen and Miller (2016) highlighted that some consumers were not willing to purchase organic foods due to lack of some special value and doubts about product guarantees in the eyes of the consumers. Still, many studies confirmed that there is segment of consumers who are health conscious and believe that organic food products are healthier and more nutritious then the conventional counterparts (Bo Won Suh et al., 2015; Madan, 2017). For example, Suh, Eves \& Lumbers (2015) with a reference to other studies have shown that Greek consumers believed that consuming organic food products positively influenced and benefitted their health. Similarly, Malaysian consumers believed that organic food is better in terms of quality and freshness, and perceived good value contribution for their health (Song \& Mansori, 2016).

Besides, Madan (2017) argues that consumers want more than just nourishment from their food as they are more educated about health and wellness than ever before. While the food is a key factor towards good health, many believe that maintaining an active lifestyle and mental well-being are important factors that contribute to emotional and physical wellbeing. Consumers agree that good health is a holistic combination of good food choices and healthy lifestyle habits (Madan, 2017). Hence, previous study confirmed the existence of positive relationship between safety and perceived value of health benefits, because consumers believe that food without chemicals and genetically modified organisms contributes to their health value (Chung \& Biing-Hwan, 2007; Song \& Mansori, 2016). Therefore, studies confirmed that health considerations have been identified as the most significant factor when selecting organic food products (Bo Won Suh et al., 2015; Pilař et al., 2018).

Additionally, to the above studies, the research analysis by Vecchio et al. (2016) showed that not only consumers appeared to be very sensitive to the health aspect of their everyday choices; trust was another factor to consider. Likewise, Song \& Mansori (2016) confirms importance of labeling and certification as important product attribute factors that positively influenced consumer's perspective of organic foods. 
Consumers have to rely on the information provided by trusted authorities to evaluate such foods as these foods have credence attribute and consumers cannot evaluate them on their own. Therefore, knowledge possessed by consumers plays a vital role in influencing consumer attitude and making a purchase decision (Vecchio et al., 2016). Thus, as assured by Suh, Eves, \& Lumbers (2015), trust has been found to have a significant influence with regards to food safety concerns and consumer food selection.

To develop consumer's trust, the USDA established the National Organic Program (NOP) to develop national standards for organically produced agricultural products and established an organic certification program as required by the Organic Foods Production Act (OFPA) passed by Congress in 1990 (Cohrssen \& Miller, 2016; Klonsky, 2012). Organic agriculture, which is governed by strict government standards, requires that products bearing the organic label are produced without the use of toxic and persistent pesticides and synthetic nitrogen fertilizers, antibiotics, synthetic hormones, genetic engineering or other excluded practices, sewage sludge, or irradiation. According to studies, organic certification guidelines are well laid out and easier for understanding organic food certification (Klonsky, 2012; Madan, 2017).

However, Cohrssen and Miller (2016) argues that national standard does not improve food safety, quality or nutrition. The authors imply that the USDA allows the use of the word organic only for marketing purposes, there is no guarantee for its safety, quality or nutrition that the labeling of organic food does not benefit consumers but is sells organic products. Whereas USDA data indicates that organic foods have fewer pesticide residues than conventionally grown produce, the amounts for both types of produce are within the level for safe consumption. Hence, it's unclear if the pesticides used in organic farming are safer than the synthetic pesticides used in conventional farming, such conclusions forces for more future studies to be made in this topic (Klonsky, 2012).

Even though there were discrepancies among researchers, the result of the further studies done by Kareklas et al. (2014) suggests that consumer purchases of organic food products may be influenced by egoistic altruistic considerations. Meaning that purchasing organic food products not only beneficial for consumers but positively contributes to the environment and society. In addition, in their research, Smith and Brower (2012) highlighted that the use of more environmentally friendly products will help managing the increasing concern about the health of the planet, social responsibility and the ethical treatment of animal. Hence, emphasizing positive impact which organic foods consumption has on well-being and its contrition to cleaner environment will be more effective and persuasive (Kareklas et al., 2014). Therefore, such an outcome is not only attractive to consumers but is benefiting advertisers. As the end result, it will lead to consumer's willingness to purchase organic food products.

In likelihood to the Kareklas et al. (2014) study, the research completed by Smith and Brower (2012) disclosed that millennials are attracted to the products which are environmentally friendly. Previous studies indicated that $47 \%$ of millennials would pay more for environmentally friendly products because they care for the environment. Products that are less harmful to the environment have been identified in several studies as desirable to consumers, even to the point of consumers being willing to pay more for these products. Studies indicate that the usage of more environmentally friendly products will help managing the increasing concern about the health consciousness of the planet. (Smith \& Brower, 2012; Chung \& Biing-Hwan, 2007). Thus, there is a huge potential for the future growth of the organic foods market.

In addition to the above factors which influences consumer purchasing decision, willingness-to-pay for particular food attributes is linked to an observation that consumers make trade-offs for improved attributes associated with consuming particular products (Bo Won Suh et al., 2015). It reflects an observation that individual preferences are unique. Given that yields are generally lower for organic production than for functional and conventional production, consumer willingness-to-pay a price premium for organic products is an important determinant of organic farm profitability and long-term financial sustainability. The magnitude of the price mark-up is also important because it helps in assessing the value consumers place on particular product attributes. A price premium on organic produce can signal differences in product attributes and characteristics and, therefore, is an important search attribute for consumers behavior towards organic foods (Vecchio et al., 2016).

\section{Research Methodology}

In the above discussion, the author conducted a literature review based on numerous research studies. Many studies concluded that the demand for organic food products is increasing due to the various factors, including nutritional benefits, health-conscious, production of high quality, food safety, environmental protection and animal welfare (Bo Won Suh et al., 2015; Cohrssen \& Miller, 2016; Madan, 2017; Pilar 2018; Pino et al., 2012; Türk et al., 2016). 
The goal of this study was to examine the factors that affect consumer's willingness to purchase organic food products. Factors such as environmental conscious, health conscious, perceived cost, labels and certification were observed and tested. A descriptive statistics analysis and a Pearson correlation test were conducted to check the association between the variables. After that, the author run a regression analysis to compare the model fit, to further analyze the data, and to understand the relationship between the variables.

\subsection{Research Framework and Hypothesis Development}

Based on the above stated objectives, the research framework was developed. The research framework explained the relationship of the independent variables and the dependent variable which are shown in Figure 3.1.1. The independent variables included environmental concern, health concern, perceived cost, labels and certification, whereas willingness to purchase organic food products was a dependent variable. The similar model was adopted from previous study conducted by Song \& Mansori (2016) and designed to accommodate current research. Hence forth, the following hypotheses were formulated to help to examine a relationship between four independent variables and one dependent variable, a consumer WTP organic food product.

Hypothesis 1: Positive perception towards environment consciousness will have positive effect on consumer willingness to purchase organic food products.

Hypothesis 2: Positive perception towards health consciousness will have positive effect on consumer willingness to purchase organic food products.

Hypothesis 3: Perceived costs about organic foods will have negative effect on consumer willingness to purchase organic food products.

Hypothesis 4: Labeling and certification on organic food products will have positive effect on consumer willingness to purchase organic food products.

Figure 3.1.1: Theoretical Framework Adapted from Song \& Mansori (2016).

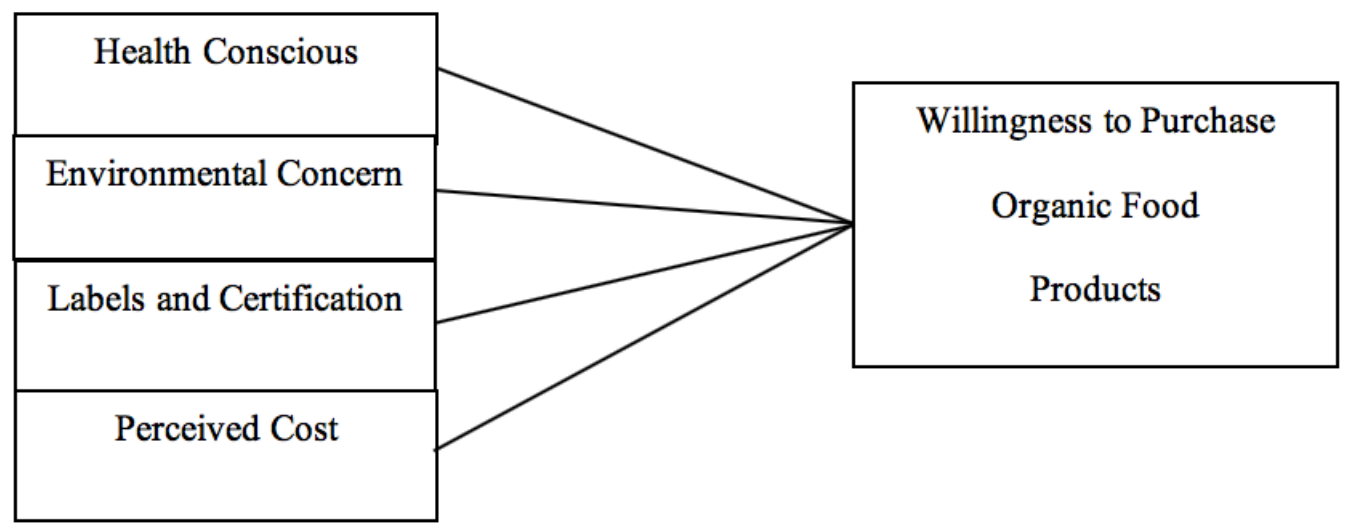

\subsection{Questionnaire}

To test the hypotheses and to meet the goal of this study, a qualitative approach approved by Wells College Institutional Review Board (IRB) was conducted. The primary data was collected through distribution of an online questionnaire using Goggle Forms. The survey instrument was designed to ask potential participants a total of twentyfour questions and was emailed to students and faculty of Wells College of Aurora, to Cornell University of Ithaca, and was posted on Facebook, from March 13, 2019 to March 22, 2019. The questions were assessed by a Likert scale, a measurement scale that consisted of five response categories ( $1=$ strongly disagree, $2=$ disagree, $3=$ neutral, 4=agree, $5=$ strongly agree) with the closed ended questions. A Likert scale was used to indicate respondent's satisfaction level of consuming organic food products (See Appendix Section 8, Sub-Section 8.2.).

\subsection{Data Analysis}

Following the data coding, the data analysis was conducted by using Microsoft Excel statistical tools for understanding of the respondent's data. Further, Karl Pearson correlation coefficient was used as a measure of reliability and to determine an overall consistency and correlation of the scale (Singhal, 2017). In addition to correlation analysis (See Appendix Section 8, Sub-Section 8.1), a regression analysis, ANOVA, was performed to determine the model fit. Then, an R-squared was examined, a statistical measurement to understand the goodness of fit, or how close the data points were positioned to the fitted regression line. Based on the R-squared value we understand the percentage of the variance in the dependent variable that is explained by the independent variable (Table 4.2.1.). 
Next, to determine the overall significance level of the model, a p-value was used to identify whether the relationship was statistically significant. The alpha $(\alpha)$ value of 0.05 was used to determine the level of significance. A p-value was used in conjunction with the t-value for better interpretation of the hypothesis. The t-test compared the data mean to what was expected under the null hypothesis. A t-value of zero indicated that the sample results exactly equaled the null hypothesis and the null hypothesis remained true. The larger the t-value, the smaller the p-value, and the greater the evidence against the null hypothesis. When the p-value is very low ( $<$ alpha level of 0.05 , the probability of making a wrong decision), the null hypothesis is rejected. The smaller the p-value the greater the evidence against the null hypothesis. Hence, the evidence in the sample data was strong enough to accept the alternative hypothesis.

\section{Research results}

\subsection{Demographic Characteristics}

Table 4.1.1 presents the demographic profile of our respondents. Due to missing values for some respondents, certain questions may not sum up to 100 percent. The summary of descriptive statistics analysis model was adopted from Singhal (2017) and was modified to fit the current study. In the total sample size of 208 participants, 172 were female (83\%); 33 participants were male (16\%), and 3 individuals identified themselves as other (1\%). According to the research, most of the respondents fall in the range from 18-34 years of old, which consists of 83 (40\%) participants; the second highest group range from 35-47 years old and consists of 57 (28\%) participants; the third group range of 48-66 years old involved 49 (24\%) participants; the forth group ranged from 67+ years old with 11(5\%) participants and lastly, participants who were under 18 years old held the lower proportion of 7 (3\%) participants. More than half of the respondent fall under "married" category and calculated to 107 participants or 52\%; 71 participants or 34\% identified themselves as "single"; 14 divorced participants or 7\%; 12 participants or 6\% identified themselves as other and finally, 2 participants or $1 \%$ fall under widow category.

Table 4.1.1. Sample Profile of Respondents $(n=208)$. Adopted from Singhal (2017)

\begin{tabular}{|c|c|c|c|}
\hline Demographic Factor & Factor Category & No. of Respondents & Percentage $(\%)$ \\
\hline \multirow[t]{3}{*}{ Gender } & Female & 172 & 83 \\
\hline & Male & 33 & 16 \\
\hline & Other & 3 & 1 \\
\hline \multirow[t]{5}{*}{ Age } & Under 18 years old & 7 & 3 \\
\hline & $18-34$ years old & 83 & 40 \\
\hline & $35-47$ years old & 57 & 28 \\
\hline & 48-66 years old & 49 & 24 \\
\hline & $67+$ years old & 11 & 5 \\
\hline \multirow[t]{5}{*}{ Marital Status } & Single & 71 & 35 \\
\hline & Married & 107 & 52 \\
\hline & Divorced & 14 & 7 \\
\hline & Widow & 2 & 1 \\
\hline & Other & 12 & 6 \\
\hline
\end{tabular}

The summary of the results shows that respondents in this sample primary identify themselves as female, are young adults and married. According to U.S. Census Bureau, in July 1, 2018 United States population estimated to 327. 2 million people, representing a 6 percent increase in population since April 1, 2010. According to the 2010 Census, the United States population was 308.7 million (Table 4.1.2.). Female persons accounted to 50.8 percent of the total population while 49.2 percent were male. Correspondingly, based on the Census 2010 fact finder, married female accounted to 60.3 million (48.3 percent) of the population, while married male accounted to 61.7 million (52.2 percent), with the median age of a population equating to 37.2 years.

Table 4.1.2. United States 2010 Census Population and Median Age

\begin{tabular}{|l|l|l|l|l|}
\hline 2010 Census Population (million) & Gender & Population Percentage (\%) & Median Age & Married (\%) \\
\hline $156,964,212$ & Female & 50.8 & 38.5 & 48.3 \\
\hline $151,781,326$ & Male & 49.2 & 35.8 & 52.2 \\
\hline $308,745,538$ & (x) & 100 & 37.2 & $(x)$ \\
\hline
\end{tabular}

Sources: U.S. Census Bureau, General Demographic Characteristics, 2010 Census, DP-1, 2006-2010 American Community Survey, DP 02. 
Therefore, in comparison to the U.S. national data, based on our results we can see how well our sample reflects the population and how valid and reliable our conclusions will be. So, the current research sample size is biased towards female population, as $83 \%$ of respondents are female, with less men $(16 \%)$ than women participating in the survey. The difference between the two is known as observed effect. We observe that that the gender effect is to reduce the proportion by $67 \%$ for men relative to women.

In addition to demographic results, the summary of regression analysis results of each respondents score is representing how well participants responses matched each factor are shown in Appendix Section 8, Sub-Section 8.2.

\subsubsection{WTP \& Environment Conscious}

Conferring to the Table 4.2.1, the value of R-squared of 0.13 shows that the environmental consciousness independent variable accounts for $13 \%$ of the variability in WTP. The $t$-value $=1.50$ indicates a positive difference between sample data and null hypothesis; a p-value of $1.20133 \mathrm{E}-07$ is less then $\alpha$-value (the significance level of 0.05 ), thus environment conscious is statistically highly significant. Therefore, based on available evidence, we reject the null hypothesis and accept the alternative hypothesis. We can conclude that alternative hypothesis 1: "Positive perception towards environment consciousness will have positive effect on consumers behavior to purchase organic food products" is true at the $95 \%$ confidence level.

\subsubsection{WTP \& Health Conscious}

According to the Table 4.2.1., the value of R-squared is 0.458 which means that independent variable health consciousness accounts for $46 \%$ of the variability in willingness to purchase. Health conscious has t-value $=5.129$; $p$ value $=3.57542 \mathrm{E}-29$ indicating that the $\mathrm{p}$-value is less than the $\alpha$-value (the significance level of 0.05 ), thus the variable health conscious is statistically highly significant. Since the p-value is very low, we reject the null hypothesis and accept alternative hypothesis. Therefore, based on the results we can conclude that there is a positive relationship between health conscious and willingness to purchase organic food products. Hence, the alternative hypothesis 2 , "Positive perception towards health consciousness will have positive effect on consumers behavior to purchase organic food products" is true at the $95 \%$ confidence level.

\subsubsection{WTP \& Perceived Expensiveness}

Table 4.2.1. indicates that perceived expensiveness accounts for $15 \%$ of the variability in willingness to purchase. Perceived expensiveness $t$-value $=20.6506$; with $\mathrm{p}<0.001 \mathrm{p}$-value $=9.07173 \mathrm{E}-09$ is less than the alpha (the significance level) value of 0.05 , therefore perceived expensiveness is statistically highly significant. Based on the research results we reject the null hypothesis and accept alternative hypothesis 3 . Therefore, the hypothesis "Perceived expensiveness about organic food products will have negative effect on consumer intention to purchase organic food products" is accepted at the $95 \%$ confidence level. Thus, we can conclude that there is a positive relationship between WTP, a dependent variable and perceived expensiveness, an independent variable.

\subsubsection{WTP \& Labels and Certification}

In Table 4.2.1., R-squared is 0.11 which shows that Labels and Certification accounts for $11 \%$ of the variability in willingness to buy. Labels and Certification t-value $=7.7048$; with $\mathrm{p}<0.001$, $\mathrm{p}$-value $=1.10508 \mathrm{E}-06$ indicating that the $\mathrm{p}$ value is less than the $\alpha$-value of 0.05 , which shows that the labels and certification, the independent variable is statistically highly significant. Thus, we reject the null hypothesis and accept the alternative hypothesis 4 , "Labeling and certification on organic food products will have positive effect on consumer intention to purchase organic food products" is true at the $95 \%$ confidence level. Hence, we can conclude that there is a positive relationship between WTP, a dependent variable and labels \& certification, an independent variable.

\subsection{Results Discussion}

This study provides an understanding of consumer willingness to purchase organic food products. Various methods were used to test the variables. At first, descriptive statistics were done on demographic profile of respondents to better understand the relationship on WTP according to gender, age and marital status. From the outcome of the analysis it was found that majority of the respondents consisted of young married adults between the age of 18-34 with female respondents dominating $(83 \%)$ the sample size. There may be several reasons for why our population is skewed toward female. Firstly, we can assume that the large gap between male and female in the sample size can be related to the gender gap at Wells College community, which mainly consisting of female students, faculty and staff. Secondly, the possibility that the Cornell University employees skewed towards female as well, or that female are more sensitive to the subject matter of organic foods. And thirdly, even though the survey circulated on Facebook platform to both gender, female was more prone to take the survey. Thus, we can make an assumption that female is more considerate and attentive in the subject matter, in particularly, organic food products. Following demographic characteristics, reliability test was carried out to determine consistency of measurement for each variable. 
Based on the results, all four variables were found to have a positive relationship with willingness to purchase organic food products, with R-square value range between 0-1(Table 4.2.1).

In addition to the above outcomes, four hypotheses were tested using regression analysis. The results of the regression analysis performed have shown that environment consciousness, health consciousness, perceived expensiveness, labeling and certification, are statistically significant with the p-value less than the alpha value of 0.001 (The results are reported in Table 4.2.1.). Hence, our study concluded that the alternative hypotheses for the above variables were true at the $95 \%$ confidence level and that there was a positive relationship between WTP, and four independent variables identified above. While demographic characteristics have shown a p-value greater than the alpha value of 0.05 , concluding that the variable are not significantly significant at the $95 \%$ confidence level.

Table 4.2.1 Regression Results and the Probability Value by Variables

\begin{tabular}{|l|l|l|l|l|}
\hline WTP \& & R-Square & T-Stat & P-Value & Results \\
\hline Environment & 0.127 & 1.5000 & $1.201 \mathrm{E}-07$ & Statistically Highly Significant $\mathrm{p}<0.001$ \\
& & & & \\
\hline Health & 0.458 & 5.1288 & $3.575 \mathrm{E}-29$ & Statistically Highly Significant $\mathrm{p}<0.001$ \\
\hline Expensiveness & 0.148 & 20.6506 & $9.072 \mathrm{E}-09$ & Statistically Highly Significant $\mathrm{p}<0.001$ \\
\hline Label Trust & 0.109 & 7.7048 & $1.105 \mathrm{E}-06$ & Statistically Highly Significant $\mathrm{p}<0.001$ \\
\hline Gender & 0.001 & 22.6977 & 0.6535991 & Not Statistically Significant $\mathrm{p}>0.05$ \\
\hline Age & 0.018 & 16.0929 & 0.0526298 & Not Statistically Significant $\mathrm{p}>0.05$ \\
\hline Marital Status & 0.001 & 34.5137 & 0.6554908 & Not Statistically Significant $\mathrm{p}>0.05$ \\
\hline
\end{tabular}

Statistically Significant at $\alpha=0.05$; Statistically Highly Significant at $\alpha=0.001$.

Moreover, results of the current study have shown that health conscious variable is affecting the most WTP and has a strong positive relationship with willingness to purchase organic food products. The health-conscious model (See Table 4.2.1.) has higher R-squared value than other tested variables and accounts to $46 \%$ of the variability in WTP denoting a better fit for the data.

This current study results were consistent with previous studies and confirms that health consciousness is the most significant factor that affecting consumer's willingness to purchase organic food products (Bo Won Suh et al., 2015; Pilař et al., 2018). This implies that consumers are aware about health and nutrition benefits of organically grown produce which influences their purchase decision.

Conferring to Table 4.2.1., perceived expensiveness $\left(\mathrm{R}^{2}=15 \%\right)$ were the next significant factors, following health consciousness, that affects consumer decisions and willingness to purchase organic food products. The results are in line with the study conducted by Song \& Mansori (2016), who have found that organic foods are generally higher priced compared to conventional foods. They confirm that the price is a significant factor that causes a barrier to consumer when purchasing organic food products. However, consumers are willing to pay higher price if they receive superior benefits from the organic foods such higher nutritional value, long term health benefits, ecology, protection of animal welfare, and ease of purchase due to availability of organic food products (Song \& Mansori, 2016). Thus, based on the research, marketers can gain a significant benefit when promoting organic food products based on the attributes that have positive effect on consumer willingness to purchase organic food product and label it accordingly to consumer desires.

Next, environmental concern has found to have a positive relationship on willingness to purchase organic food products with R-squared of $13 \%$ variability in WTP. It is observed that environmental consciousness is another factor that that encourages consumers to purchase organic foods. With this in mind, organic food marketers can benefit by focusing on such audience which in return will increase the demand for organic food products and will be beneficial to the economy overall.

Labels and certification followed environmental consciousness results with R-squared variability of $11 \%$ in WTP. The result was consistent with previous study by Song \& Mansori (2016) and verifies the importance of labeling and certification as a factor that positively influences consumer's willingness to purchase organic foods. Therefore, our study confirms that knowledge about organic food labeling possessed by consumers plays a vital role in making a purchasing decision. Besides, stricter laws can be implemented to monitor organic producers to ensure farmers compliance with organic food guidelines established by USDA. Thus, it is important for marketers of organic food products to keep these objectives and values in mind when producing organic food products, considering price, ensuring its availability, and designing their advertisements to encourage the purchase of organic food products which in turn will benefits the economy. 
Finally, as mentioned above, gender, age, and marital status have insignificant p-value, which requires further investigation to gain better insight into the type relationship between given set of variables. From a marketing standpoint, based on research findings variable such as gender, age and marital status are not a good indicator of WTP for organic food products. However, the fact that younger and married adults are likely to purchase more of organic food products suggests that targeting and advertising to this group may be affective. So, promoting organic food products could be targeted to this audience. From the labeling model, organic labeling and pro-organic messages about the importance of the organic standards could increase this factor further. Our study suggests, that health variable can have the most powerful advertisement effect when promoting organic food products by identifying the benefits of organically grown produce to the consumer.

\section{Conclusion}

In our study, we combined and reviewed available literature to provide an understanding of consumer preferences toward willingness to purchase organically grown foods and conducted research analysis to show the relationship between variables. The findings of this research are consistent with many previous studies (Bo Won Suh et al., 2015; Pilařet et al., 2018). Notably, health consciousness is shown to be the most important factor influencing consumer willingness to purchase organic food products. Besides health consciousness, the findings of the current research have shown that consumer preference for organic food products is based on a general perception that organic has more desirable characteristics than conventionally grown alternatives. Human health, along with several other product characteristics such as environmental consciousness, cost, labeling and certification of organic food products influences consumer preferences to purchase organic food products. Thus, consumer willingness to purchase organic food products reflect not only a confirmation that individuals make trade-offs between attributes associated with consuming alternative products, but also a confirmation that individual consumer preferences are unique.

Some limitations to the current study were discovered: missing factors in demographic characteristics such as income level and education level could enhance the results of the study and their effect on consumer willingness to purchase organic food products. Also, variables such as quality and variety of organic foods may be observed and compared to conventional foods, a greater sample size could bring more accurate results. Lastly, the survey questions could be constructed differently, since a consumer-based approach to understanding organic agriculture is important not only in its own right, but also in terms of responses to changes in market dynamics. Most studies on consumer knowledge about organic agriculture reflect a conceptual belief that is true and justified and tend to use research methods that rely on correctness to answers to survey questions. Correct or incorrect responses imply knowledge and awareness about organic food products. Though, his notion of consumer knowledge and awareness has some limitations and does not capture some important aspects of knowledge. Hence, we suggest addressing the limitations stated above for a future research.

\section{References}

Bo Won Suh, Eves, A., \& Lumbers, M. (2015). Developing a Model of Organic Food Choice Behavior. Social ehavior \& Personality: An International Journal, 43(2), 217-230. https://zeus.wells.edu:2610/ 10.2224/s bp. 2015.43.2.217

Chenglin, Liu. (2011). Is "USDA Organic" A Seal of Deceit?: The Pitfalls of USDA Certified Organics Produced in The United States, China and Beyond. Stanford Journal of International Law, 47(2), 333-378. Retrieved from http://zeus.wells.edu:2067/login.aspx?direct=true \&db=buh\&AN=66621661\&site=ehost-live \&scope=site

Chung L. Huang, \& Biing-Hwan Lin. (2007). A Hedonic Analysis of Fresh Tomato Prices among Regional Markets. Review of Agricultural Economics, 29(4), 783-800. https://zeus.wells.edu:2610/10.1111/j.1467-9353.2007 $.00387 . \mathrm{x}$

Cohrssen, J. J., \& Miller, H. I. (2016). The Usda’s Meaningless Organic Label. Regulation, 39(1), 24-27. Retrieved fromhttp://zeus.wells.edu:2048/login?url=http://search.ebscohost.com/login.aspx?direct=true\&db=buh\&AN=1 $14666885 \&$ site $=$ ehost-live \&scope $=$ site

Istudor, N., \& Pelau, C. (2013). Impulsive buying behavior depending on gender. International Journal of Management Science \& Technology Information, (10), 157-165. Retrieved from http://zeus.wells.edu:2048/login? url=http://search.ebscohost.com/login.aspx?direct=true \&db=buh\&AN=113484038\&site=ehostlive \&scope $=$ site

Kareklas, I., Carlson, J. R., \& Muehling, D. D. (2014). "I eat organic for my benefit and yours": egoistic and altruistic considerations for purchasing organic food and their implications for advertising strategists. Journal of Advertising,(1),18.Retrievedfromhttp://zeus.wells.edu:2048/login?url=http://search.ebscohost.com/l ogin.aspx? direct=true $\& \mathrm{db}=$ edsgbe $\& A N=$ edsgcl.360679075\&site=eds-live $\&$ scope $=$ site 
Karen Klonsky. (2012). Comparison of Production Costs and Resource Use for Organic and Conventional Production Systems. American Journal of Agricultural Economics, 94(2), 314. https://zeus.wells.edu:2610/10.1093/ajae/aar102

Madan, M. A. (2017). Empirical study on preference of millennials towards healthy food products with respect to organic and functional foods. Indian Journal of Health \& Wellbeing, 8(6), 460-469. Retrieved from http://zeus.wells.edu:2048/login?url=http://search.ebscohost.com/login.aspx?direct=true\&db=a9h\&AN=12514 $2804 \&$ site $=$ eds-live $\&$ scope $=$ site

Pilař, L., Stanislavská, L. K., Gresham, G., Poláková, J., Rojík, S., \& Petkov, R. (2018). Questionnaire vs. Social Media Analysis - Case Study of Organic Food. Agris On-Line Papers in Economics \& Informatics, 10(3), 93-101. https://zeus.wells.edu:2610/10.7160/aol.2018.100308

Pino, G., Peluso, A. M., \& Guido, G. (2012). Determinants of regular and occasional consumers' intentions to buy organic food. Journal of Consumer Affairs, (1), 157. Retrieved from http://zeus.wells.edu:2048/login?url=http://search.ebscohost.com/login.aspx?direct=true $\& \mathrm{db}=$ edsgbe $\& A N=$ edsgcl $.286390104 \&$ site $=$ eds-live $\&$ scope $=$ site

Singhal, N. (2017). A Study of Consumer Behavior Towards Organic Food and the Moderating Effects of Health Consciousness. IUP Journal of Marketing Management, 16(3), 45-79. Retrieved from http://zeus.wells.edu :2048/login?url=http://search.ebscohost.com/login.aspx?direct=true\&db=buh\&AN=124880564\&site=ehostlive\&scope $=$ site

Song Bee Lian, Safari, M., \& Mansori, S. (2016). The Effects of Marketing Stimuli Factors on Consumers' Perceived Value and Purchase of Organic Food in Malaysia. Jurnal Pengurusan, 47, 1-19. Retrieved from http://zeus.wells.edu:2048/login?url=http://search.ebscohost.com/login.aspx?direct=true\&db=buh\&AN=11863 $9938 \&$ site $=$ ehost-live \&scope $=$ site

Smith, K. T., \& Brower, T. R. (2012). Longitudinal study of green marketing strategies that influence Millennials. Journal of Strategic Marketing, 20(6), 535. Retrieved from http://zeus.wells.edu:2048/login?url=http:// search.ebscohost.com/login.aspx?direct=true $\& \mathrm{db}=\mathrm{edb} \& \mathrm{AN}=82052547 \&$ site=eds-live $\&$ scope $=$ site

Türk, B., \& Erciş, A. (2017). 4A Marketing Mix Impacts on Organic Food Purchase Intention. Serbian Journal of Management,12(2),189.Retrievedfromhttp://zeus.wells.edu:2048/login?url=http://search.ebscohost.com /login.aspx?direct=true

Vecchio, R., Van Loo, E. J., \& Annunziata, A. (2016). Consumers' willingness to pay for conventional, organic and functional yogurt: evidence from experimental auctions. International Journal of Consumer Studies, 40(3), 368-378. https://zeus.wells.edu:2610/10.1111/ijcs.12264

\section{Bibliography}

U.S. Census Bureau. American FactFinder, Profile of General Population and Housing Characteristics: 2010, Demographic Profile Data, 2010 Census, DP-1, Retrieved on April 27,2019from https://factfinder.census.gov/faces/tableservices/jsf/pages/productview.xhtml?src=bkmk.

U.S. Census Bureau. American FactFinder, Selected Social Characteristics in the United States. 2006-2010 American Community Survey 5-Year Estimates, Census 2010, DP02. Retrieved on April 27, 2019 from

https://factfinder.census.gov/faces/tableservices/jsf/pages/productview.xhtml?pid=ACS_17_5YR_DP02\&src=pt

\section{Appendix}

\subsection{Data Analysis: Correlation Matrix}



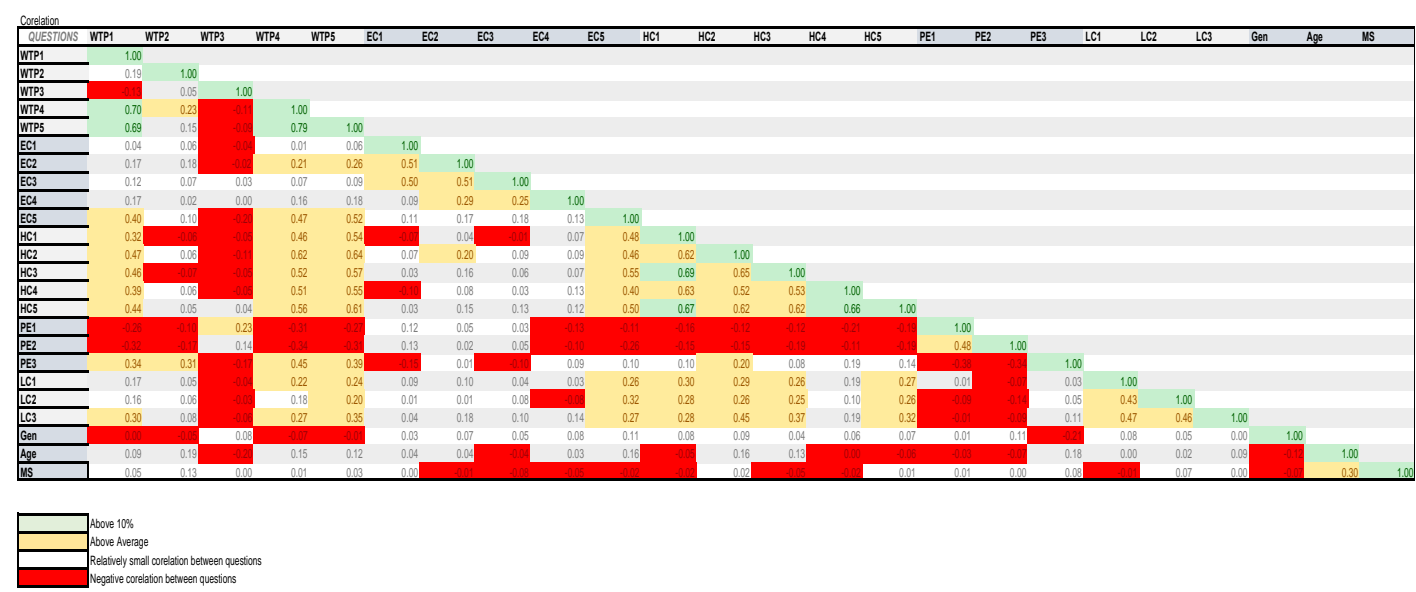

Figure 8.1.1. Correlation Matrix

The green color shows above $10 \%$ correlation; the yellow color shows above average correlation; the white color shows relatively small correlation; and the red color shows a negative correlation between questions.

\subsection{Institutional Review Board (IRB) Application}
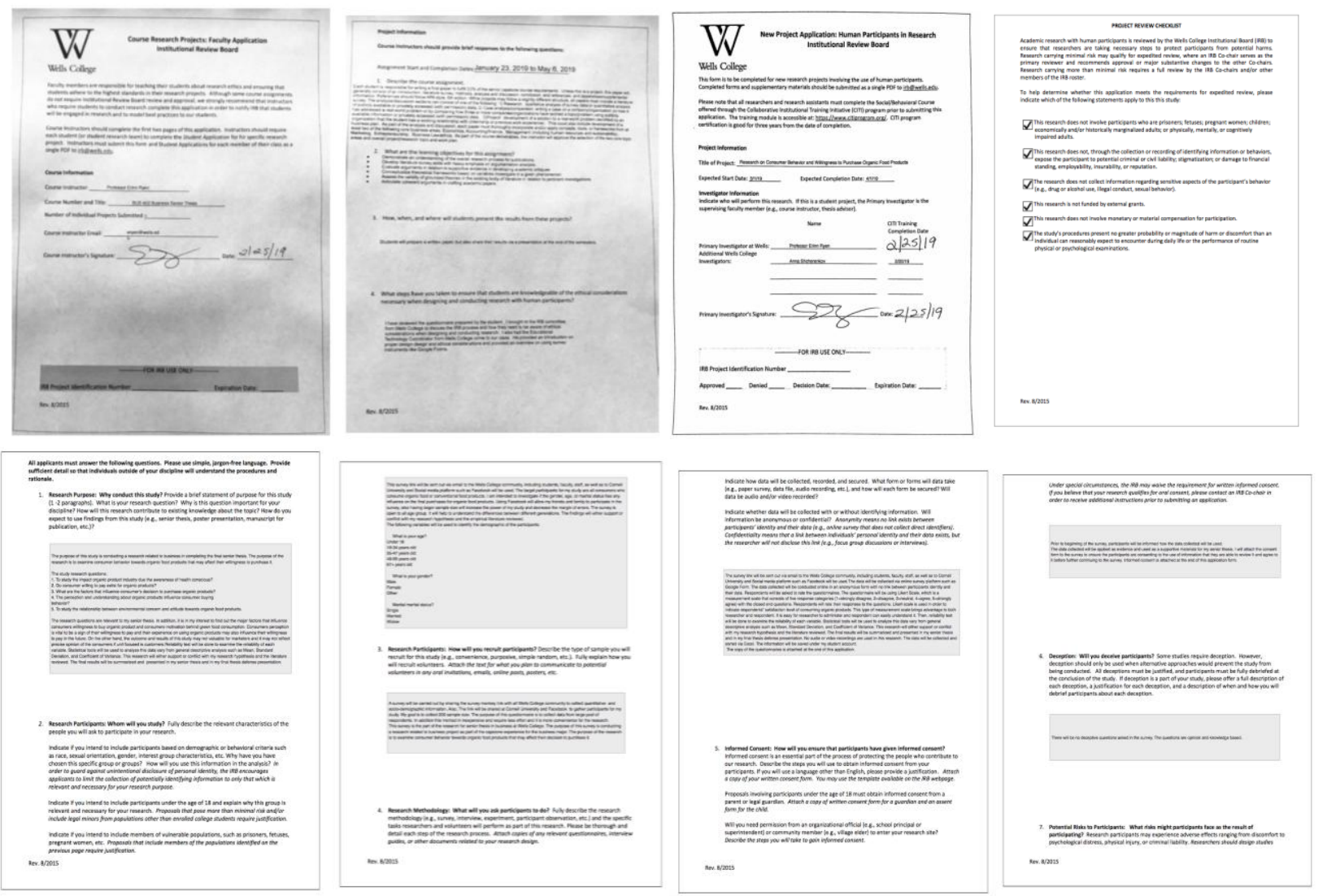

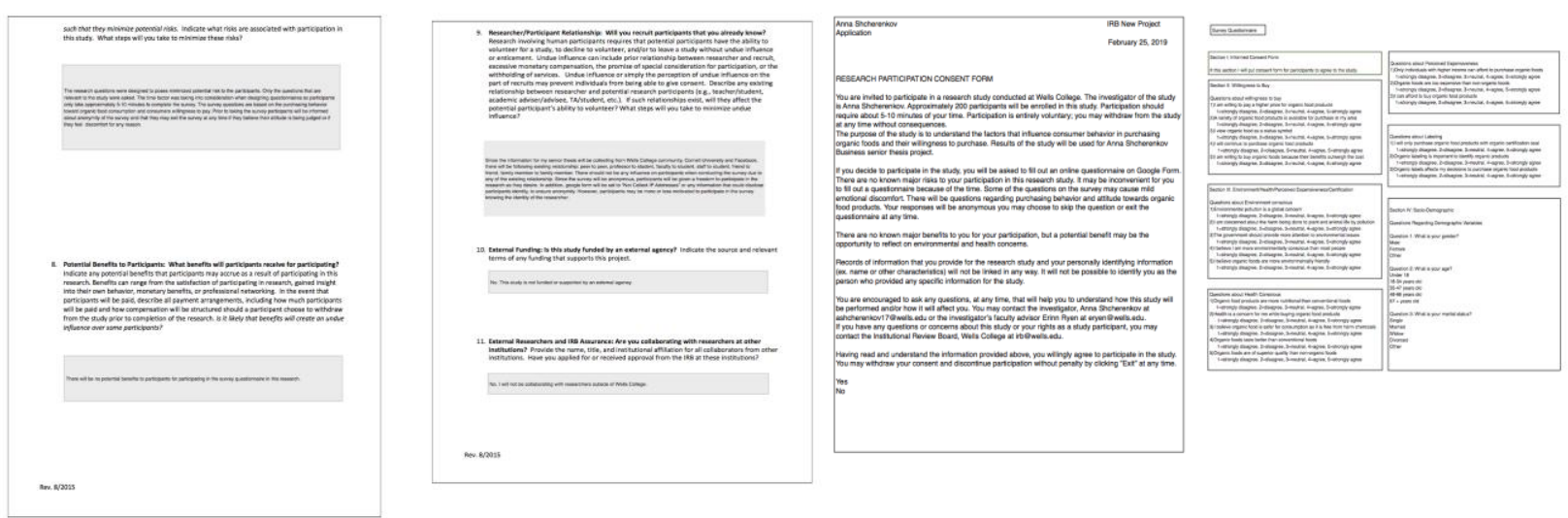